\title{
Cryopreservation of Brassia rex Orchid Shoots Using PVS2 Technique
}

\begin{abstract}
In vitro grown shoots of Brassia rex orchid hybrid was cryopreserved by means of plant vitrification solution 2 (PVS2) technique. For the preculture treatment, the shoots were excised into two standard sizes of 0.5-1.0 and 1.0-1.5 $\mathrm{cm}$ and were precultured on halfstrength Murashige and Skoog (MS) semi solid medium supplemented with different concentrations of sucrose (control $(0.06 \mathrm{M}), 0.1,0.25,0.5$ and $0.75 \mathrm{M})$ for 24 and $48 \mathrm{~h}$. For the PVS2 dehydration treatment, the $0.1 \mathrm{M}$ precultured $(48 \mathrm{~h}$ and $1.0-1.5 \mathrm{~cm}$ ) shoots were chosen for further experiment where the shoots were dehydrated in PVS2 solution at various durations $(5,10,15,20,25$ and $30 \mathrm{~min})$ at 0 and $24^{\circ} \mathrm{C}$ for positive and negative storage in Liquid Nitrogen (LN). The viability of the cryopreserved cells were determined by 2, 3, 5triphenyltetrazolium chloride (TTC) assay and chlorophyll extraction techniques. The best condition of PVS2 treatment was at 20 min of PVS2 treatment at $0^{\circ} \mathrm{C}$ prior to storage in liquid nitrogen. In chlorophyll determination based on chlorophyll assay, the highest concentration of total chlorophyll concentration $(56.250 \mu \mathrm{g} g-1)$ was obtained from shoots that were dehydrated for $25 \mathrm{~min}$ in PVS2 solution at $0^{\circ} \mathrm{C}$ without storage in liquid nitrogen.
\end{abstract}

Keyword: Brassia rex Orchid, PVS2 Technique 